\title{
Book review: Twenty-Five Years on the Cutting Edge of Obsidian Studies: Selected Readings from the IAOS Bulletin
}

\author{
Sean G. Dolan \\ Environmental Stewardship (EPC-ES) Los Alamos National Laboratory, Los Alamos, New Mexico, USA. \\ Email: sgdolan@lanl.gov
}

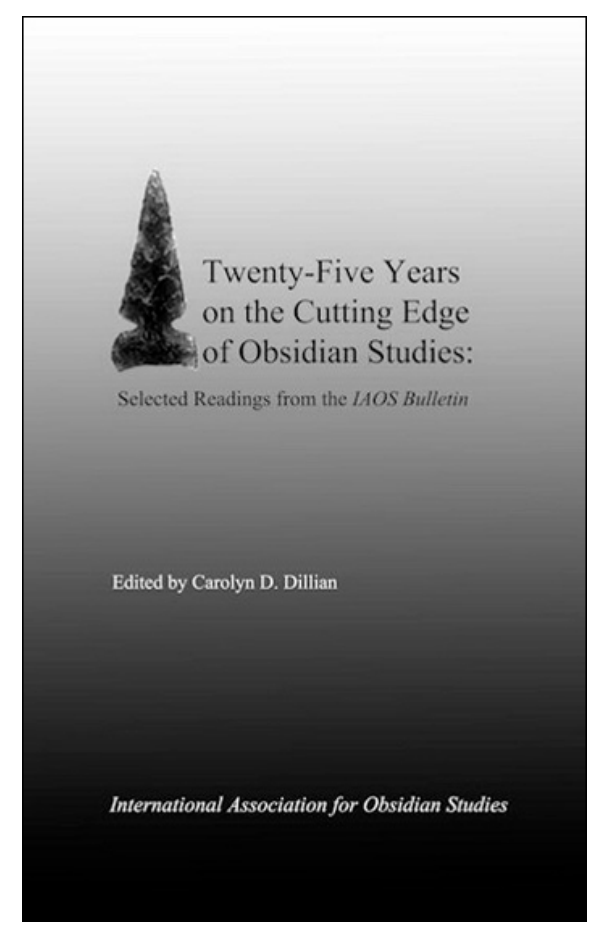

Twenty-Five Years on the Cutting Edge of Obsidian Studies: Selected Readings from the IAOS Bulletin

Edited by Carolyn D. Dillian

International Association for Obsidian Studies, 2014, pp. 188. ISBN 978-0-615-96888-9

http://members.peak.org/ obsidian/iaos_publications.html

Edited by Carolyn D. Dillian (Coastal Carolina University), Twenty-Five Years on the Cutting Edge of Obsidian Studies: Selected Readings from the IAOS Bulletin consists of 19 previously published articles from the International Association for Obsidian Studies (IAOS)

Published by the School of History, Classics and Archaeology, University of Edinburgh ISSN: 2055-0472. URL: http://journals.ed.ac.uk/lithicstudies/

This work is licensed under a Creative Commons Attribution 2.5 UK: Scotland License. 
Bulletin. Dillian selected these articles because they provide a range of methodological and theoretical approaches concerning archaeological obsidian studies from around the world like Eretria, California, and the Near East, for example.

The volume is organized into three main topics, (1) obsidian hydration dating, (2) source characterization, and (3) case studies. The first three chapters are introductory. Dillian introduces the volume in Chapter 1 . In Chapter 2, Hull discusses the many reasons behind the establishment of the IAOS. These include, to provide an avenue and a means for reporting analytical standards for laboratory comparability, to report on hydration and sourcing results from around the world, to provide an opportunity for training and to develop workshops, and to give researchers a central hub for all things obsidian. It is in my opinion that these goals that were first outlined more than 25 years ago were accomplished with the assistance and hard work of many archaeologists, researchers, and laboratory workers. This is shown in many of the publications in this volume. Originally published in 1995 when the Internet was in its infancy, Skinner (Chapter 3) discusses how the World Wide Web could be used as a way to distribute archaeological and obsidian information to the masses. Skinner created a PDF database available on the IAOS website of theses and dissertations, and other articles published concerning obsidian hydration and sourcing. Maps illustrating where obsidian sources are located are also available on the website. Although more work needs to be conducted to extend the coverage of obsidian source maps in more places where outcrops are present, researchers who are interested in North American sources will be pleased.

Chapters 4-7 are concerned with obsidian hydration dating. Stevenson et al. (Chapter 4) report on the results of a study that compares obsidian hydration rind measurements between six researchers from multiple laboratories to determine if their results are comparable. It turns out there was good agreement between all involved. Rondeau (Chapter 5) provides examples of how the integration of obsidian hydration dating with lithic analysis can help to better understand the temporal placement of the knapping and recycling of obsidian artifacts from California. Although he does not test his examples, he provides a framework for future research.

Unlike Rondeau's article that attempts to combine method and theory with obsidian hydration and lithic technology, Rogers in Chapter 6 is solely concerned with making obsidian hydration methods more available to the "mathematically disinclined". Rogers "cook book" for California obsidian hydration is a good start for archaeologists interested in the mathematics behind hydration dating. However, for someone who is mathematically challenged, I had difficulty fully understanding it. The last chapter in this section is by Liritzis (Chapter 7). He describes recent advances in hydration dating using secondary ion mass spectrometry (SIMS) using samples from the Aegean.

Authors in Chapters 8-11 report on obsidian characterization or sourcing information. In the opening chapter, Frahm asks the question, what is an obsidian source? Should archaeologists/researchers use the term source to describe the chemical signature, or should they use it for the place on the landscape where people procured the obsidian? Later in the article, he uses a phenomenological approach to explore new ways of thinking about obsidian sources. This chapter, in my opinion, is a breath of fresh air and one of the more important contributions to this volume. It includes a pathway for integrating anthropological theory with archaeometric techniques. This is something more archaeologists who use chemical sourcing should apply to their research. Similar to the contributions made in Chapter 4, Glascock in Chapter 9 discusses reports on results of an inter-laboratory comparison of element compositions for two obsidian sources (Pachuca in Hidalgo, Mexico, and the Little Glass Buttes in Oregon, USA). Labs from around the world participated in this experiment, and a host of destructive and non-destructive geochemical techniques were used. The purpose of 
this research was to give a comparative database for self-examination, but Glascock does not evaluate or comment on the accuracy or precision of the results.

Because some obsidian sources have similar trace elemental compositions and it is difficult to determine one geographically distant source from another, Bellot-Gurlet et al. (Chapter 10) used particle-induced x-ray emission (PIXE) to source samples and Fission Track Dating to provide better chronological control on obsidian artifacts in Columbia and Ecuador. In Chapter 11, Poupeau and colleagues used Mössbauer spectroscopy (MS) rather than x-ray fluorescence (XRF) spectrometry or neutron activation analysis (NAA) to determine the provenance of obsidian artifacts from Eastern Anatolia where it is difficult to discriminate peralkaline samples. Their results hold promise for using MS in future studies because this method not only determines the primary outcrop from which obsidian artifacts derive from, but it also helps to locate the precise flow location or specific workshop the artifact was procured from.

Research reported in Chapters 12-19 combine obsidian hydration and/or sourcing to answer archaeological questions. Garfinkel et al. (Chapter 12) examined two obsidian bifaces from California. Hydration and sourcing demonstrates one biface is from the West Sugarloaf Mountain (Coso) source and dates to the thirteenth century A.D., while the other is from the Bodie Hills source and dates to the Paleoindian period. Obsidian sourcing research in the north-central Mesoamerican frontier in Durango, Zacatecas, and Jalisco is limited compared to studies further south in Mesoamerica. In Chapter 13, Darling remedies this problem by sourcing artifacts along the southern Sierra Madre Occidental. In Chapter 14, Boulanger and colleagues discuss the likely source of a Paleoindian obsidian artifact from Louisiana. No obsidian outcrops exist in the eastern United States, so if obsidian artifacts are found in archaeological contexts there it can be attributed to long-distance trade and exchange. Therefore, the presence of an obsidian Paleoindian artifact in this part of the country is a significant find. Previous sourcing analysis on this artifact yielded an unknown source, but Boulanger and colleagues compared the trace element concentrations with updated sourcing databases. The most-likely source of the artifact is the Pumice Hole Mine subsource of the Mineral Mountain Range source in Utah, but the chemical signature is also similar to the Wild Horse Canyon source also located in Utah. Using inductively coupled plasma mass spectrometry (ICP-MS) López and colleagues (Chapter 15) examined two previously unknown obsidian sources to provide models of trade and circulation in La Pampa, northwest Patagonia in Argentina. Poupeau and colleagues (Chapter 16) discuss how more on the ground survey is needed to determine the primary and secondary obsidian source distribution in the East Göllü Dağ area in Turkey before more archaeological interpretations are given. People in Eretria along the Red Sea coast during the Late Stone Age primarily used obsidian to manufacture stone tools. Unfortunately, few sourcing studies have been conducted in this part of the world, and the primary and secondary source locations for most obsidians is unknown. As a result, Glascock, Beyin, and Coleman (Chapter 17) used XRF and NAA to resolve source characterization issues.

With the increasing availability and further refinement of portable XRF (PXRF) spectrometry in field archaeology and museum studies to source obsidian and other materials, Torrence and colleagues (Chapter 18) describe a useful method for mounting the PXRF instrument to reduce the risk of damaging the object being sourced. Because PXRF is portable, it opens the door to source objects that possibly cannot leave museums because they are too fragile, or due to their culturally sensitive nature. This chapter is especially pertinent for archaeologists in the United States where the Native American Graves Protection and Repatriation Act (NAGPRA) plays a role in access to some artifacts. For instance, obsidian projectile points are sometimes found next to human remains, and they are considered sacred. PXRF may be the best way to source obsidian artifacts that cannot leave museums since they 
are awaiting repatriation. In the last chapter of the volume, Frahm (Chapter 19) reviews the seminal contributions made by Sir Colin Renfrew, John Dixon, and Joseph Cann early on in obsidian sourcing studies to understand which sources people used in the Near East.

Twenty-Five Years on the Cutting Edge of Obsidian Studies: Selected Readings from the IAOS Bulletin should be on the book shelves of seasoned archaeologists who study obsidian. This volume is also a good starting point for students or newcomers into the field who are interested in learning about the development of obsidian hydration, source characterization, and how some archaeologists have applied hydration and sourcing methods to answer archaeological questions throughout the world. The articles in this volume really speak to the development and worldwide expansion of obsidian studies. This is one of the contributions of the IAOS because there are papers concerning obsidian from all over the globe.

Readers of Journal of Lithic Studies who are mostly interested in lithic technology and the organization and production of stone tools will be dismayed, however. Few authors discuss the manufacture and use of obsidian stone tools. On the other hand, archaeologists interested in methods and case studies concerning hydration dating and chemical sourcing will be stimulated. This volume is helpful to archaeologists who are interested in learning more about the many methods for determining hydration rates and chemical composition for sourcing. However, Frahm (Chapter 8:65) importantly points out, "it is easy, in obsidian sourcing research, to spend considerable time and effort developing the instrumentation and data analysis." Without proper methods and researchers who know how to operate the equipment correctly, we cannot answer our archaeological questions. The case studies in this volume are a welcome addition to help connect method with theory. The articles in this volume, along with other IAOS Bulletin publications are available as free PDFs from the IAOS website. However, archaeologists who are interested in all things obsidian can purchase this volume on their website for $\$ 10.00$ (USD). 